Caligrama, Belo Horizonte, v. 23, n. 2, p. 183-198, 2018

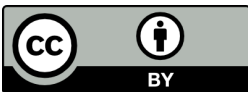

\title{
"Proyecciones del desamparo": reflexões sobre a violência na literatura de Roberto Bolaño
}

\section{"Proyecciones del desamparo": reflections on violence in the literature of Roberto Bolaño}

\author{
Júlia Morena Costa \\ Universidade Federal da Bahia, Salvador, Bahia / Brasil \\ juliamorenacosta@gmail.com
}

Resumo: $O$ presente artigo objetiva analisar a abordagem da violência, em especial a que atinge as mulheres, na literatura de Roberto Bolaño (1953-2003). Considerando que as manifestações de violência são um elemento de grande presença na obra do autor, sejam as históricas ou as cotidianas, formando um mapa geográfico, temporal e histórico de suas diversas irrupções, propõe-se analisá-las de forma relacionada. Para isso, são retomados episódios significativos nos diversos livros que compõem a obra do autor, com ênfase na "Parte de los crímenes" de 2666, e são realizadas reflexões sobre as tramas que permitem a invisibilização da problemática social tratada nos diversos textos de Bolaño (FEMENÍAS, 2007; ROJO, 2010 e BENJAMIN, 2012), assim como sobre as relações do literário com o real (SCHØLLHAMMER, 2012).

Palavras-chave: violência; Roberto Bolaño; feminicídio.

\begin{abstract}
This article aims to analyze the approach of violence, especially that which affects women, in the literature of Roberto Bolaño (1953-2003). Considering that manifestations of violence are greatly present in the author's work, both in a historical sense and in daily life, this study aims to make sense of the geographical, temporal, and historical settings in which they occur. In order to accomplish this, significant episodes from the various books that make up the author's work were analyzed, with an emphasis on the "Parte de los crímenes" of 2666. From there, the article describes the features of these plots in the various texts of Bolaño that allow for the continued invisibility of social problems (FEMENÍAS, 2007, ROJO, 2010 and BENJAMIN, 2012), as well as the relationship between literature and the real world (SCHØLLHAMMER, 2012).
\end{abstract}

Keywords: violence; Roberto Bolaño; feminicide. 
Todo es proyección de un muchacho desamparado... pura violencia.

(BOLAÑO, 2002, p. 94)

A violência é um tema de central importância na atualidade, em especial na América Latina. Com números crescentes de mortes por assassinatos, o continente americano marca presença constante nos rankings das cidades mais violentas do mundo. Em um levantamento realizado em 2014 pelo Consejo Ciudadano para la Seguridad Pública y La Justicia Penal, organização civil mexicana, das 50 cidades mais violentas do mundo, 41 estão na América Latina e Caribe, das quais 16 são brasileiras e 9 são mexicanas (SÁNCHEZ, 2014). A já famosa Ciudad Juárez, ${ }^{1}$ cidade do norte mexicano que inspirou a Santa Teresa de Roberto Bolaño, figurou como primeira da lista em 2008, 2009 e 2010, passando a segunda em 2011 e estando, atualmente, ainda presente no ranking, na $37^{a}$ posição. No contexto brasileiro, de acordo com o estudo Mapa da violência 2013: homicídios e juventude no Brasil, promovido pelo Centro de Estudos Latino-Americanos (CEBELA), entre 1980 e 2011, a morte de jovens por homicídios teve um aumento de 326\% (WAISELFISZ, 2013, p. 17). O estudo aponta que, embora o Brasil não esteja em conflito direto com outros países, nem apresente enfrentamentos religiosos, disputas territoriais e terrorismos ou guerras civis declaradas, foi contabilizado, entre 2008 e 2011, um total de 206.005 vítimas de homicídios. Este número é superior aos dos doze maiores conflitos armados que aconteceram no mundo entre 2004 e 2007 e é quase idêntico ao total de mortes diretas registradas nos 62 conflitos armados deste período (WAISELFISZ, 2013, p. 21). Em 2011, o país registrou 52.198 vítimas de homicídio, o que representa 143 assassinatos a cada dia desse ano. A maioria dos crimes acomete as populações mais fragilizadas socialmente, incidindo principalmente sobre os jovens negros. ${ }^{2} \mathrm{O}$ autor da pesquisa,

\footnotetext{
${ }^{1}$ Sobre Ciudad Juárez, Bolaño a associa com o inferno e afirma: "Como Ciudad Juárez, que é nossa maldição e nosso espelho, o espelho desasosegado das nossas frustrações e da nossa infame interpretação da liberdade e dos nossos desejos" (BRAITHWAITE, 2013, p. 77, tradução minha). Texto original: "Como Ciudad Juárez, que es nuestra maldición y nuestro espejo, el espejo desasosegado de nuestras frustraciones y de nuestra infame interpretación de la libertad y de nuestros deseos.".

${ }^{2}$ Dos 467,7 mil homicídios contabilizados entre 2002 e 2010, 65,8\% foram de negros. É preciso ainda ressaltar que todos estes números são oficiais e, portanto, provavelmente
} 
Julio Jacobo Waiselfisz, afirma que "há um mecanismo perverso que incentiva a tolerância à violência contra os grupos mais vulneráveis, que deveriam ter proteção do Estado: tornar a vítima culpada. Isso ocorre com mulheres, crianças e jovens marginalizados qualificados como traficantes, drogados e arruaceiros" (SARRES, 2013). O universo de Bolaño e a maior incidência da violência rondaram, ambos, os mesmos ambientes e os personagens mais marginalizados, sendo estes os mais vulneráveis. Outro importante estudo, também de autoria de Julio Jacobo Waiselfisz, o Mapa da violência 2012 - homicídio de mulheres no Brasil, aponta que "nos 30 anos decorridos entre 1980 e 2010 foram assassinadas no país acima de 92 mil mulheres, 43.700 só na última década" (WAISELFISZ, 2012 , p. 8). Apenas no ano de 2012, foram registrados 4.465 assassinatos de mulheres e $70.285^{3}$ casos de violência contra mulheres no país. Destes, $71,8 \%$ ocorreram dentro da própria residência das vítimas, o que permite entender que é no âmbito doméstico que se gera a maior parte das situações de violência contra mulheres. O relatório aponta, também, que os altos índices de feminicídio frequentemente são acompanhados de um alto nível de tolerância da violência contra mulheres. Tal violência pode ser entendida, ainda, como fruto da referida tolerância, se considerarmos os casos de reincidência de agressões já anterioremente registradas e que seriam, portanto, passíveis de serem evitadas.

Os dados de homicídio, embora se restrinjam às formas mais extremas da agressão - não abordando ainda as suas inúmeras manifestações -, permitem entrever a magnitude da violência no Brasil, no México e nos demais países da América Latina. A partir dessas informações, que serão retomadas ao longo deste estudo, pode-se perceber a importância do tema para a atualidade e para a discussão

menores que os índices reais, gerando uma sub-anotação devido ao sepultamento sem o competente registro, seja por limitações da cobertura do sistema do Ministério da Saúde, seja pelos interesses de ocultamento das causas de morte.

${ }^{3}$ Optei por trazer tantos dados, incluídos os brasileiros, para tratar da dimensão da problemática da violência em toda a América Latina, que, apesar das especificidades de cada país, apresenta semelhanças consideráveis. Sobre os casos específicos de feminicídio apresentados, pareceu-me importante marcar o lugar brasileiro como de intensa proximidade aos demais territórios latino-americanos. Os crimes de feminicídio no Brasil, assim como os de Ciudad Juárez e os de Santa Teresa de Bolaño, são numerosos e escandalosos, sendo praticados com requintes de crueldade e terror e contando com grande tolerância social, como foi apontado pelos estudos acima referidos. 
cultural e de suas diversas produções no continente. Abordá-lo já seria, em si, um ato político e de posicionamento frente a uma constituinte tão presente e opressora desta sociedade. No entanto, tratar da violência e relacioná-la a suas diferentes manifestações, como faz Bolaño em sua literatura - com maior ou menor grau de cotidianidade, de modo mais explicitamente histórico ou aparentemente inofensivo, em diferentes épocas ou variadas geografias etc.-, pode ser ainda mais potente. Roberto Bolaño, à sua maneira, constrói um mapa geográfico, temporal e histórico das diversas manifestações da violência, relacionando as suas formas e explicitando o que há de comum entre todas elas: a permissividade quanto às agressões e a intolerância à existência do que não é normativo.

A violência é um elemento constante nas obras narrativas de Roberto Bolaño. A partir de diferentes formas, ela aparece em todos os seus livros, embora em cada momento se apresente sob um viés distinto. Em seus romances e contos, seja de forma explícita ou não, a violência figurará como um dos elementos centrais que afetará seus personagens, provocando traumas, construindo seu caráter e sendo, muitas vezes, responsável por seu deslocamento espacial e temporal nas narrativas. Em muitos casos, são os traumas gerados por uma violência sofrida que farão com que os personagens busquem em suas memórias uma forma de recontar, reelaborar e tentar superá-los. É também a partir de casos de violência que muitos deles vão ter que deixar suas cidades e casas, partindo para um deambular sem destino.

A partir do olhar da violência, os livros de Bolaño, ao serem lidos em conjunto, apresentam uma verdadeira enciclopédia do horror. Há mostras de uma profusão de suas mais diversas formas. Além dos romances que escancaram o padecimento político que acometeu o Chile a partir de 1973, como Nocturno de Chile e Estrella distante (cuja crueldade está condensada na figura de Wieder), ou o feminicídio escandaloso de 2666, seus livros estão semeados por brutalidades múltiplas. Por um lado, há uma violência histórica reiterada e que perpassa todos os seus textos, com mais ou menos intensidade, mas sempre presente (Golpe de 1973 no Chile e suas reverberações; massacre de Tlatelolco no México; Segunda Guerra Mundial). Por outro, há uma crueldade cotidiana constante. As duas, juntas, se relacionam e são tratadas como inevitáveis, onipresentes e dissolvidas na rotina e na biografia dos seus personagens. Em sua literatura, alguns acontecimentos podem parecer irrelevantes, mas corroboram a violência analisada: a agressividade, a crueldade e a 
intolerância - as mesmas apresentadas quando referidas aos massacres históricos presentes em seus textos - deslizam para as relações cotidianas sem que os indivíduos se deem conta.

Essa latência da agressividade e crueldade se encontra mesmo nos romances que, à primeira vista, se distanciam da violência institucionalizada ou social dos regimes ditatoriais. O machismo, presente em quase todos os textos, se manifesta em comentários misóginos ou na homofobia, que parte até mesmo dos colegas de militância esquerdista, como é bem tratado em "Ojo Silva": "pessoas de esquerda que pensavam, pelo menos da cintura para baixo, exatamente igual que a pessoas de direita que naquele momento tomava posse do Chile"4 (BOLAÑO, 2008, p. 7). A tortura aparece de forma dissimulada no conto "Putas asesinas" e mais explicitamente nos porões de María Canales em Nocturno de Chile. As prisões políticas e o terror psicológico advindo delas são retratados de tempos em tempos e acometem B, Belano ou o personagem Roberto Bolaño. A profusão das mais diversas brigas pessoais, entre elas a que culmina na morte de Cesárea Tinajero em Los detectives salvajes. Perseguições inúmeras, sequestros e assassinatos políticos, como as causadas por Wieder. A exploração sexual como da prostituta Lupe, que tenta fugir de seu cafetão e cuja fuga é o estopim da viagem do quarteto em Los detectives salvajes. As opressões e imposições de cunho religioso, como também em "Ojo Silva". Além, claro, das omissões do Estado, que se traduzem no abandono sofrido pelos habitantes de Santa Teresa, seja quando desaparecem os entes queridos, seja no tratamento dado ao tráfico, outra forma de violência que movimenta toda uma máfia e, sabe-se, é responsável pelo financiamento de atentados nas mais diversas esferas e com cumplicidade do governo.

Para analisar as possíveis tramas da violência na obra de Roberto Bolaño, tomo como exemplo primeiro a sequência de feminicídios de Santa Teresa apresentada em 2666, por entendê-la como um ponto nevrálgico e de intensa explicitação do horror humano. Ao longo da análise, este exemplo se relaciona e se desdobra em outros eventos que mantém estreita afinidade com as suas formas de fomento. ${ }^{5}$ Como

\footnotetext{
4 "gente de izquierdas que pensaba, al menos de la cintura para abajo, exactamente igual que la gente de derecha que en aquel momento se enseñoreaba de Chile" (BOLAÑO, 2001, p. 6). ${ }^{5}$ É interessante notar que, na "Parte de los crímenes", no ano que dá início à narrativa de mortandade das mulheres, a primeira a morrer é a Esperanza e a última, a Felicidad: "E
} 
apontado anteriormente, a maior parte da violência acomete justamente os setores mais fragilizados da sociedade, seja pela falta de apoio social, seja pelo pouco apelo que têm junto àqueles que poderiam ser responsáveis por sanar tal opressão. Essa crueldade e agressividade latentes em Bolaño geram em seus personagens, principalmente nos já marginalizados, a consciência do abandono, o medo e o desespero da impotência frente a uma violência já disseminada e endêmica, contra a qual o indivíduo pouco ou nada pode fazer. Tal sistemática leva a uma angustiante passividade e falta de perspectiva de ação contra a opressão dessa crueldade. O vazio, então, apresenta-se como único horizonte. Emblemático é o exemplo de 2666, das últimas mortas de 1996, Estefanía Rivas, de 15 anos, e Herminia Noriega, de 13. As duas foram sequestradas por um carro preto, o mesmo responsável por outros sequestros de meninas, enquanto caminhavam em direção à escola, junto de suas irmãs menores. As duas pequenas, após um momento de inércia diante do ocorrido, se dirigem à própria casa, onde não há ninguém. Pedem auxílio à vizinha, que tenta entrar em contato com os pais das jovens. No entanto, a fábrica, na qual trabalhavam, friamente não permite a comunicação com seus funcionários. Impotente ante a indiferença da fábrica e do abandono do poder público, e diante da escassez de recursos materiais, a vizinha, já sem moedas para fazer chamadas, senta-se junto às meninas e, desconsoladas,

experimentaram o que era estar no purgatório uma longa espera inerme, uma espera cuja coluna vertebral era o desamparo, algo muito latino-americano, por outra parte, uma sensação familiar, algo que, se parasse para pensar bem, experimentava todos os dias, mas sem angústia, sem a sombra da morte sobrevoando o bairro como uma debandada de gaviões e deixando tudo espesso, transtornando a rotina de tudo, pondo todas as coisas ao revés. ${ }^{6}$ (BOLAÑO, 2004, p. 659-660, tradução minha, grifos meus.)

esse foi o último assassinato de uma mulher em 1993, que foi o ano em que começaram os assassinatos de mulheres naquela região da república mexicana" (BOLAÑO, 2004, p. 492, tradução minha). Texto original: "Y ese fue el último asesinato de una mujer en 1993, que fue el año en que comenzaron los asesinatos de mujeres en aquella región de la república mexicana".

6 "experimentaron lo que era estar en el purgatorio una larga espera inerme, una espera cuya columna vertebral era el desamparo, algo muy latinoamericano, por otra parte, una sensación familiar, algo que si uno lo pensaba bien experimentaba todos los días, pero sin angustia, sin la sombra de la muerte sobrevolando el barrio com"o una 
Esta passagem, que evoca o desamparo latino-americano cotidiano, expõe as sistemáticas que desvalorizam a vida das populações marginalizadas e contribuem para a violação dos direitos e da proteção destas: o poder das empresas que ignoram a humanidade de seus funcionários, enquanto os exploram como mão de obra descartável somada à inoperância de um poder público que deveria proteger essa população (ainda que ao longo das páginas desse subcapítulo estes episódios sejam recorrentes, inclusive com o uso do mesmo carro e do mesmo procedimento de sequestro e assassinato de mulheres na região, nada é feito para impedi-lo.). O trecho citado faz, ainda, uma extensão desse momento específico de abandono e violência particular das irmãs do norte mexicano para os demais territórios do continente, criando uma relação direta dessa violência e do abandono como imagem construída de toda a América Latina.

É preciso recordar que a inadequação dos processos modernizatórios e neoliberais na América Latina são causadores de imensas violências e corrupções que mantêm sua população refém até a atualidade. A exploração da mão de obra que chega ao norte do México para trabalhar nas fábricas está intimamente relacionada à violência praticada ali, de desrespeito total a essa população, que é descartável e silenciada, desumanizada e, portando, cujas mortes não causam comoção, pelo menos não o suficiente para grandes e necessárias mudanças. Nesse cenário, o sexismo pode se manifestar com muita tranquilidade. As mulheres foram incluídas no mercado de trabalho de forma mais intensificada, mas não foi feita a correspondente inserção social de sua presença nos espaços públicos. Se, por um lado, houve a necessidade de frequentar os territórios comuns, por outro, não se procedeu ao preparo da sociedade para a plena inserção e presença das mulheres como indivíduos de igual direito. $\mathrm{E}$ as violências exercidas nos espaços públicos, como explica Ana Falú (2009, p. 21, tradução minha), "adquirem expressões similares àquelas que ocorrem portas adentro e que avassalam seus corpos; agressões que curiosamente são catalogadas como 'crimes passionais', que contam com um alto grau de tolerância social e que, por fim, ainda culpam as

debandada de zopilotes y espesándolo todo, trastocando la rutina de todo, poniendo todas las cosas al revés." 
vítimas". ${ }^{7}$ Assim, as mulheres ocupam um lugar precário socialmente e não são vistas como dotadas da mesma humanidade que os homens. Tal "descompasso", entre intensificação do ingresso no mercado de trabalho e na vida social desvinculado de uma inserção na cidadania plena, provoca uma hostilidade e tentativas de expulsão desse segmento social dos espaços compartilhados. Maria Luisa Femenías (2007, tradução minha), discorrendo sobre a desigualdade e a violência de gênero na América Latina, aponta que

ao marco formal igualitário e universalista, ao qual respondem em maior ou em menor medida todas as nossas constituições - que resultaram insuficientes historicamente -, devemos somar um conglomerado de questões materiais. Sobretudo, na medida em que o proclamado universal poucas vezes se aplicou distributivamente por igual a todos os membros da sociedade, discriminando por sexo-gênero, por etnia e por classe. ${ }^{8}$

O aviltamento da vida dos cidadãos, sobretudo aqueles que estão historicamente à margem, é a fonte estrutural da violência em Bolaño, em que o Estado, muitas vezes, é omisso ante às frequentes irrupções de agressividade, omissão essa que, neste sentido, pode ser tão violenta quanto os governos institucionalmente autoritários, como era o Chile pinochetista, por exemplo.

Um dos mecanismos que dificultam a proteção aos grupos vulneráveis, como mencionado, é a culpabilização das vítimas pela agressão sofrida. Trata-se de encontrar supostos motivos para o ataque, principalmente associando os sujeitos a um grupo marginal, ao qual seria mais aceitável tal agressão. Essa estratégia camufla a nefasta tolerância às violências simbólicas e físicas a determinados segmentos da população,

\footnotetext{
7 "Adquieren expresiones similares a las de aquellas que tienen lugar puertas adentro y que avasallan sus cuerpos; agresiones que curiosamente son catalogadas como 'crímenes pasionales', que cuentan con un alto grado de tolerancia social y terminan culpabilizando a las víctimas".

8 "al marco formal igualitario y universalista, al que responden en mayor o en menor medida todas nuestras constituciones -que ha resultado históricamente insuficiente-, debemos sumarle un conglomerado de cuestiones materiales. Sobre todo, en la medida en que el proclamado universal pocas veces se aplicó distributivamente por igual a todos los miembros de la sociedad, discriminando por sexo-género, por etnia y por clase".
} 
que no julgamento social não seriam merecedores de iguais direitos à defesa de sua integridade.

Em "La parte de los crímenes", Bolaño desnuda esse mecanismo. No episódio do desaparecimento de Lucy Anne, diante da denúncia de sua amiga Érica, não há grande mobilização por parte da polícia, que pensa que as duas podem ser prostitutas e, portanto, em sua lógica perversa, menos confiáveis e dignas de proteção:

Foi atendida por um homem que dizia se chamar Kurt A. Banks, que lhe fez toda classe de perguntas sobre sua amiga e sobre ela mesma, como se não acreditasse em nada da versão que Erica tinha lhe contado. Somente ao sair dali Erica compreendeu que o cara suspeitava que tanto Lucy Anne quanto ela eram putas. ${ }^{9}$ (BOLAÑO, 2004, p. 510, tradução minha)

Outro personagem, o jornalista Sergio González, também comete o mesmo equívoco e, ao perguntar a uma prostituta que havia contratado sua opinião sobre as mortes em Santa Teresa, tem uma revelação. A prostituta não demonstra grande comoção pelo relato do jornalista. $\mathrm{O}$ fato

reuniu a irritação de Sergio, que exasperado lhe disse que em Santa Teresa estavam matando putas, que pelo menos demonstrasse um pouco de solidariedade gremial, ao que a puta the respondeu que não, que tal como ele tinha contado a história, as que estavam morrendo eram operárias, não putas. Operárias, operárias, disse. E então Sergio lhe pediu perdão e como se tivesse sido tocado por um raio viu um aspecto da situação que até este momento tinha passado batido. ${ }^{10}$ (BOLAÑO, 2004, p. 583, tradução minha)

\footnotetext{
9 "La atendió un tipo que decía llamarse Kurt A. Banks, que le hizo toda clase de preguntas acerca de su amiga y de ella misma, como si no creyera para nada la versión que Erica le había dado. Sólo al salir de allí Erica comprendió que el tipo sospechaba que tanto Lucy Anne como ella eran putas."

10 "concitó el enojo de Sergio, quien exasperado le dijo que en Santa Teresa estaban matando putas, que por lo menos demostrara un poco de solidaridad gremial, a lo que la puta le contestó que no, que tal como él le había contado la historia las que estaban muriendo eran obreras, no putas. Obreras, obreras, dijo. Y entonces Sergio le pidió perdón y como tocado por un rayo vio un aspecto de la situación que hasta ese momento había pasado por alto."
} 
Nessa constatação, há o desnudamento do machismo intrínseco na percepção das mortes e (des)valorização das mulheres vítimas, associando a violência sofrida ao exercício de sua sexualidade, destacando-se a hostilidade com que as mulheres operárias estavam sendo tratadas em Santa Teresa. Tal observação deixa entrever também a intolerância quanto ao ingresso das mulheres no campo de trabalho, como assinalado anteriormente, ao apontar que a maior parte das vítimas são operárias.

$\mathrm{O}$ narrador também deixa entrever as violências cotidianas que são cúmplices da violência desoladora que assola Santa Teresa: omissão da polícia e das demais autoridades, que pouco ou nada fazem para resolver a situação; ${ }^{11}$ misoginia nos comentários da polícia, dos presos, dos maridos etc.; falta de denúncia; quase total ausência de interesse nas averiguações jornalísticas. ${ }^{12}$ Aliás, a misoginia e a homofobia ultrapassa este romance e se apresentam como faces do machismo que perpassa toda a obra de Roberto Bolaño, denunciando a assiduidade de tal violência nos mais diversos meios sociais, políticos e geográficos. ${ }^{13}$

Roberto Bolaño, em "La parte de los crímenes", de 2666, faz uso de fichas policiais como escritura, sendo a maioria baseada em registros de assassinatos ocorridos em Ciudad Juárez. Com essa escolha, além de se aproximar de uma tendência da arte contemporânea de usar arquivos reais, o autor insere na arte uma realidade que desborda da ficção. Karl

${ }^{11}$ Um exemplo, recorrente, é o descaso da polícia durante as investigações, como de Beverly Beltrán Hoyos: "A zona do crime não foi rastreada e ninguém tirou moldes das numerosas pegadas que havia no lugar." (BOLAÑO, 2004, p. 631, tradução minha). Texto original: "No se rastreó la zona del crimen ni nadie tomó moldes de las numerosas huellas que había en el lugar."

${ }^{12}$ Durante toda a "Parte de los crímenes", há uma preocupação na representação dos grupos feministas, pequenos, porém resistentes, que dão pistas de uma cultura tolerante com a violência de gênero. Ainda que denunciem os casos de estupros e assassinatos, são pouco ouvidas e quase nada é feito para sanar os problemas.

${ }^{13}$ É importante notar que as inúmeras cenas de violências contra mulheres presentes na obra do autor contrastam com as relações amorosas estabelecidas por seus personagens que, de modo geral, consideram as mulheres como sujeitos e respeitam sua liberdade e autonomia sexual, como nas relações entre os críticos e Norton; de Nuria e Remo Morán; entre os jovens poetas de Los detectives salvajes; ou Juan de Dios Martínez e Elvira Campos; de Amalfitano e sua filha Rosa ou de sua mãe, Lola, entre tantos outros exemplos. Tal contraste deixa ainda mais evidente a violência de gênero presente nos casos de 2666 e nas manifestações machistas de outros personagens. 
Erik Schøllhammer (2012, p. 130) concorda com Hal Foster (2014) quando diz que há uma paixão pelo real por parte tanto dos realistas quanto dos seus críticos mais severos, seja na sua afirmação ou na sua negação. Schøllhammer (2012, p. 132) aponta ainda para a "procura de uma arte e uma literatura performática capaz de interferir sem mediação no mundo e expressar sua realidade crua", fazendo surgir um

\begin{abstract}
realismo "extremo" que procura expressar os eventos com a menor intervenção e mediação simbólica e provoca fortes efeitos estéticos de repulsa, desgosto e horror. Ou seja, a obra se torna referencial e real nesta perspectiva na medida em que consiga provocar efeitos sensuais e afetivos parecidos ou idênticos aos encontros extremos e chocantes com os limites da realidade. (SCHØLLHAMMER, 2012, p. 133).
\end{abstract}

No entanto, o que Bolaño aponta ao adotar uma atitude de transparência em relação aos eventos de Ciudad Juárez é para uma intervenção na realidade de que trata ficcionalmente. Mais do que uma inserção dos registros tal qual se encontram nas delegacias e boletins necrológicos, há uma proposta ficcionalizante, que caminha não em direção ao documentário, mas sim em direção à ficção, e acusa a cotidianidade das mortes e a insensibilidade da sociedade ao seu redor. ${ }^{14}$ A crueza com que Bolaño trata as mortes de mulheres em 2666 é uma esterilização do simbólico. Nos detalhes físicos das torturas ou lacerações daqueles corpos sem vida, não cabem metáforas ou eufemismos. É a violência crua e exaustiva através dos inúmeros casos, mas que, a cada nova ficha, deixa entrever as ferramentas de um sistema cotidianamente violento. As conversas entre os policiais, a omissão da mídia ou do governo, a violência doméstica e a reiterada justificativa que culpabiliza as vítimas mostram o outro lado dessa violência física, estampada nos informes e boletins de ocorrência policiais e declarações mortuárias.

Nesse uso de boletins policiais ficcionais, pode-se entrever duas montagens. A primeira no que se refere à totalidade das fichas transcritas e a segunda na relação destas com as investigações e a sociedade que

\footnotetext{
${ }^{14}$ Outro ponto a se considerar nas narrativas de Bolaño é a incerteza expressa nos referentes que poderiam fazer alusão a uma realidade, na forma de titubeios. Também ressalto os dados pessoais das vítimas que não poderiam constar em boletins policiais, com informações íntimas e anteriores ao crime.
} 
as contextualiza. Os detalhes contidos nos boletins, supostamente irrelevantes para as investigações policiais, como a cor do sapato ou as conquistas pessoais daquela mulher agora sem vida, são justamente o que os une e denuncia onde está o problema. A aparente falta de motivo para as mortes é que revela seu fundamento: o machismo que gera a violência de gênero, cuja mais nefasta forma é o feminicídio. É na montagem desses arquivos policiais que se percebe o elo entre todos: uma ficha isolada pode dar a saber o crime passional ou circunstancial, mas a junção de todas as fichas e a gratuidade das mortes permitem entrever que o traço comum é o machismo e a misoginia. Na segunda montagem proposta, associando as fichas com a pouca seriedade e aprofundamento das investigações, compõe-se um quadro em que o descaso com a vida dessas mulheres é patente, denunciando-se o sexismo endêmico e estrutural desta sociedade que permite o assassinato de tantas mulheres. Uma sociedade cúmplice, como repetidas vezes o relato deixa entrever: "Em meados do mês de novembro, Andrea Pacheco Martínez, de treze anos foi raptada ao sair da escola secundária técnica. Ainda que a rua não estivesse de modo algum deserta, ninguém presenciou o fato." (BOLAÑO, 2004, p. 490, tradução minha, grifos meus). ${ }^{15}$ É recorrente o relato de corpos não notados pelas pessoas que estavam em volta ou de meninas que são sequestradas sem que ninguém consiga reconhecer o raptor. Essa cumplicidade e tolerância à violência contra mulheres é ainda explicitada na pouca importância midiática desses incidentes, contrastada com a importância midiática recebida pelo profanador de igrejas da região. Um atentado ao patrimônio consegue maior notoriedade e preocupação que a morte e desaparecimento de centenas de mulheres, exibindo-se a disparidade nas valorizações entre um crime e outro.

A história macro faz desaparecer as realidades cotidianas. Mas a retomada de arquivos permite entrever aqueles detalhes que escapam da sistematização de um acontecimento. $\mathrm{O}$ mais concreto não cabe nos grandes relatos. E, por consequência, não permite denunciar a violência como dado incrustado na rotina. Por isso, o uso de fichas investigativas ficcionais com dados pessoais, mínimos, habituais, como a roupa que usava, o início de um novo curso etc., ao mesmo tempo em que humaniza

15 "A mediados del mes de noviembre Andrea Pacheco Martínez, de trece años, fue raptada al salir de la escuela secundaria técnica. Pese a que la calle no estaba desierta en modo alguno, nadie presenció el hecho." 
a vítima, traz o cotidiano para a esfera do sensível e o torna analisável, revelando a banalidade também desta violência (que não rompe o fazer diário de Santa Teresa, mas pelo contrário, o reafirma). Abel Romero, em conversa com Belano em Los detectives salvajes, anuncia a problemática de revelar e lidar com a violência incrustada em um cotidiano: "Belano, falei, o cerne da questão é saber se o mal (ou o delito ou o crime ou como quiser chamar) é casual ou causal. Se for causal, podemos lutar contra ele, é difícil de derrotar, mas há uma possibilidade, mais ou menos como dois boxeadores do mesmo peso. Se é casual, pelo contrário, estamos fodidos" $" 16$ (BOLAÑO, 2006, p. 401). Uma vez mais, a aparente falta de motivo é explicitada como uma forma ainda mais perversa de exercício da violência, por denotar o quanto a referida opressão é já um dado constitutivo e aceito da sociedade e, portanto, de combate mais difícil.

O cotidiano é uma categoria da realidade que nunca se interrompe. É uma superfície infinitamente profunda e de capacidade inesgotável de absorção. Uma obra que se propõe a interromper a violência pontual corre o risco de ser puramente retórica, pois a violência já está inscrita social e culturalmente no cotidiano. Em contraponto, uma obra que denuncia essa inscrição banalizada na rotina pode operar discursivamente, tal como faz a obra de Roberto Bolaño. O narrador de Nocturno de Chile alerta para esta banalização: "Porque o costume relaxa toda preocupação, porque a rotina suaviza todo horror." ${ }^{17}$ (BOLAÑO, 2010, p. 142, tradução minha). A banalidade, como Grínor Rojo (2010) aponta, é uma categoria pretensamente inofensiva de redundância e resistência à mudança do senso comum, que se permite estar isenta de questionamentos ou análises. Apresenta-se como uma insuspeita reafirmação do já dado, não permitindo que nesse cotidiano se rompa a aceitação das violências já instituídas, mas pelo contrário, reafirmando-as na sua mais suposta e "inocente" naturalidade. Mas Rojo (2010, p. 99, tradução minha) alerta que "o sentido comum é o resíduo de um ditame que a doxa hegemônica impôs e generalizou faz muito tempo e cuja naturalização hoje lhe serve

16 "Belano, le dije, el meollo de la cuestión es saber si el mal (o el delito o el crimen o como usted quiera llamarle) es casual o causal. Si es causal, podemos luchar contra él, es difícil de derrotar pero hay una posibilidad, más o menos como dos boxeadores del mismo peso. Si es casual, por el contrario, estamos jodidos" (BOLAÑO, 1998, p. 397). 17 "Porque la costumbre distiende toda preocupación, porque la rutina matiza todo horror." 
de respaldo para levar suas operações a um bom porto.". ${ }^{18}$ E claro que "A banalidade não só não é a tonta inocente que ela aparenta ser, mas sim uma solapada e feroz colaboradora do mal"19 (ROJO, 2010, p. 104, tradução minha).

Benjamin (2012, p. 13) também nos recorda que "a tradição dos oprimidos ensina-nos que o “estado de exceção' em que vivemos é a regra”. Portanto, afirmar e enaltecer a brutalidade de um momento específico, como se fosse uma exceção, é negar e ocultar a violência contínua e onipresente. É silenciar que esse fato específico de agressões guarda estreita relação com um continuum de violência e com seu contexto e, portanto, também com tentativas de ocultamento das suas inter-relações. Por isso, a percepção da montagem de todas as fichas policiais, revelando seu fio condutor, pode ser uma potência para esta análise.

Roberto Bolaño propõe justamente uma costura entre as diversas crueldades e agressões, de modo a fazê-las dialogar e construir uma história pautada por elas. Sua obra está marcada pela constância de uma violência similar, que, sendo parte de uma mesma, somente se apresenta de formas variadas: na obra do autor, a costura da história é justamente a partir da violência, que está presente rotineiramente na nossa sociedade, que em alguns eventos se manifesta como pico, mas nunca como ineditismo. Na sua obra, os momentos históricos não estão isolados uns dos outros e muito menos do cotidiano: são parte constituinte deste e estão entrelaçados com outros eventos de colossal violência. O feminicídio de Santa Teresa encontra seus antecedentes nas mortes de mulheres provocadas por Wieder, ${ }^{20}$ de Estrella distante, sob o comando da ditadura chilena, do mesmo modo que é antecedido pelos diversos massacres anteriores, como o de Tlatelolco, de Amuleto. É nessa aposta que, em 2666, são relacionadas as violências da ditadura chilena pela figura de Amalfitano, a Segunda Guerra Mundial e o nazismo, por Archimboldi, e o feminicídio gritante em Santa Teresa, como uma malha

18 "O sentido común es el residuo de un dictamen que la doxa hegemónica impuso y generalizó hace mucho tiempo y cuya naturalización hoy le sirve de respaldo para llevar sus operaciones a buen puerto."

19 "La banalidad no sólo no es la tonta inocente que ella aparenta ser sino una solapada y feroz colaboradora del mal."

${ }^{20}$ Wieder, o poeta vanguardista de Estrella distante que, sob ordens da repressão pinochetista, assassinava principalmente mulheres e fez do próprio trabalho violento uma pretensa obra de arte fotográfica que condensava todo o horror de seus atos. 
de um mesmo elemento, todas se encontrando em um mesmo lócus: o deserto de Sonora, a última fronteira antes dos Estados Unidos, esse último território latino-americano.

\section{Referências}

BENJAMIN, W. O anjo da história. Tradução de João Barreto. Belo Horizonte: Autêntica Editora, 2012.

BOLAÑO, Roberto. 2666. Barcelona: Editorial Anagrama, 2004.

BOLAÑO, Roberto. Amberes. Barcelona: Editorial Anagrama, 2002.

BOLAÑO, Roberto. Estrella distante. Barcelona: Editorial Anagrama, 1996.

BOLAÑO, Roberto. Los detectives salvajes. Barcelona: Editorial Anagrama, 1998.

BOLAÑO, Roberto. Nocturno de Chile. Barcelona: Editorial Anagrama, 2010.

BOLAÑO, Roberto. Os detetives selvagens. Tradução de Eduardo Brandão. São Paulo: Companhia das Letras, 2006.

BOLAÑO, Roberto. Putas asesinas. Barcelona: Anagrama, 2001.

BOLAÑO, Roberto. Putas assassinas. Tradução de Eduardo Brandão. São Paulo: Companhia das Letras, 2008.

BRAITHWAITE, Andrés. Bolaño por si mismo: entrevistas escogidas. Santiago: Ediciones Universidad Diego Portales, 2013.

FALÚ, Ana. Mujeres en la ciudad: de violencias y derechos. Santiago de Chile: Red mujer y Hábitat de América Latina, Ediciones SUR, 2009.

FEMENÍAS, María Luisa. Esbozo de un feminismo latinoamericano. Revista Estudos Feministas, Florianópolis, v. 15, n. 1, jan./abr. 2007. Não paginado. Disponível em: <http://www.scielo.br/scielo.php?script=sci arttext\&pid=S0104-026X2007000100002> . Acesso em: 5 nov. 2017.

FOSTER, Hal. O retorno do real. Tradução de Célia Euvaldo. São Paulo: Cosac Naify, 2014. 
ROJO, Grínor. Discrepancias del bicentenario. Santiago de Chile: LOM, 2010.

SÁNCHEZ, José Antonio Ortega. Por tercer año consecutivo, San Pedro Sula es la ciudad más violenta del mundo. Mexico: CCSPJP, 2014. Disponível em: <http://www.seguridadjusticiaypaz.org.mx/biblioteca/ prensa/send/6-prensa/177-por-tercer-ano-consecutivo-san-pedro-sulaes-la-ciudad-mas-violenta-del-mundo>. Acesso em: 5 jan. 2018.

SARRES, Carolina. Pesquisa mostra que negros são maioria das vítimas de homicídio. $E B C$, Brasília, 18 jul. 2013. Não paginado. Disponível em: $<$ http://www.ebc.com.br/noticias/brasil/2013/07/pesquisa-mostra-quenegros-sao-maioria-das-vitimas-de-homicidios $>$. Acesso em: 5 jan. 2018 SCHØLLHAMMER, Karl Erik. Realismo afetivo: evocar realismo além da representação. Estudos de Literatura Brasileira Contemporânea, Belo Horizonte, n. 39, jan./jun. 2012, p. 129-148. Disponível em: <http://www. anais.letras.ufmg.br/>. Acesso em: 5 nov. 2016.

WAISELFISZ, J. J. Mapa da violência 2012: atualização: homicídio de mulheres no Brasil. Rio de Janeiro: CEBELA, FLACSO Brasil, 2012. Disponível em: <http://mapadaviolencia.org.br/pdf2012/ MapaViolencia2012_atual_mulheres.pdf>. Acesso em: 6 abr. 2016.

WAISELFISZ, J. J. Mapa da violência 2013: homicídios e juventude no Brasil. Brasília: Secretaria-Geral da Presidência da República, Secretaria Nacional de Juventude, 2013. Disponível em: <https:/www. mapadaviolencia.org.br/pdf2013/mapa2013_homicidios_juventude. pdf $>$. Acesso em: 6 abr.2016. (WAISELFISZ, 2013, p. 17)

Recebido em: 29 de abril de 2018. Aprovado em: 4 de junho de 2018. 